\title{
Çocuk ve adölesanlarda vücut kitle indeksi ortalama trombosit hacmini etkiler mi?
}

\section{Does body mass index affect mean platelet volume in childhood and adolescence?}

\author{
Neslihan KARAKURT' 1 , Havva Nur PELTEK KENDIRCi²
}

'Ondokuz Mayıs Üniversitesi Tıp Fakültesi, Çocuk Sağlığı ve Hastalıkları ABD, Hematoloji BD, Samsun/TÜRKiYE ${ }^{2}$ Hitit Üniversitesi Hastanesi, Çorum Eğitim ve Araştırma Hastanesi, Çocuk Endokrinolojisi Bölümü, Çorum/TÜRKiYE

\section{Öz}

Amaç: Çocukluk çağındaki obezite ile ortalama platelet volümünün (MPV) ilişkisini araştıran çalışmalar daha çok adölesan dönemi içermektedir. Daha küçük yaştaki çocuklardaki obezitenin MPV'ye etkisi ve yaşa göre zayıf hastalarda MPV değişiklikleri tanımlanmamıştır.

Bu çalışmanın birinci sonlanım noktası obez, yaşa göre normal ve düşük VKi'ne sahip çocuk ve adölesanlarda MPV değerlerinin incelenmesidir.

Gereç ve Yöntemler: Üç yıllık hastane verilerinden yararlanılarak çocuk endokrinoloji polikliniğine başvuran hastaların dosyaları retrospektif incelendi. Hastalar vücut kitle indekslerine göre obes, normal ve zayıf olarak gruplara ayrıldı. Grupların MPV değerleri kıyaslandı.

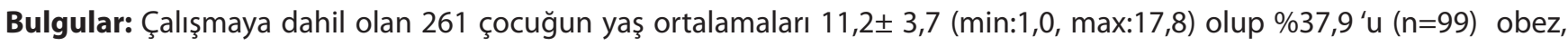
$\% 27,6$ 'sı ( $n=72$ ) yaşa göre zayıf, \%34,5 i $(n=90)$ ise normal ağırlıkta (kontrol grubu) bulundu. Tüm hastaların hemoglobin ve MPV değerleri normal aralıkta olup obez ve kontrol gruplarında yaşa göre zayıf gruba göre yüksek bulundu. Ayrıca insülin direnci olan/ olmayanlar arasında da MPV değerleri arasına istatistiksel olarak anlamlı bir fark tespit edilemedi.

Sonuç: Çalışmamızda literatürden farklı olarak MPV değerinin zayıf çocuklarda normal kiloda ve obez olanlara göre düşük, ancak hepsinde de normal aralıkta olduğunu saptadık. İnsülin direncinin MPV değerlerine etkisi olmadığını gösterdik. MPV değerlerinin klinik uygulamalarda yeri ile ilgili daha çok çalışmaya ihtiyaç vardır.

Anahtar kelimeler: çocuk, adölesan, vücut kitle indeksi, MPV, insulin direnci, hepatosteatoz

Sorumlu Yazar*: Neslihan Karakurt, Ondokuz Mayıs Üniversitesi Tıp Fakültesi, Çocuk Sağlığı ve Hastalıkları ABD, Hematoloji BD, Samsun/TÜRKiYE E-posta: neslihankarakurt@gmail.com

ORCID: 0000-0001-5487-9785

Gönderim: 05.02.2019 Kabul: 22.04.2019

Doi: $10.18663 / \mathrm{tjcl} .522291$ 


\begin{abstract}
Aim: Studies concerning relationship between obesity in childhood and mean platelet volume (MPV) are limited to adolescence period. Affect of obesity on MPV in younger children and changes in MPV levels in underweight has not been established. We aimed to evaluate MPV levels in obese, normal weight and underweight children (according to body mass index).
\end{abstract}

Material and Methods: Three year-old period of medical records of patients attending pediatric endocrinology are examined retrospectively. Patients are categorized as obese, normal and underweight for age, according to body mass indexes. MPV levels are compared between groups.

Results: 261 children were included in study. The mean age was 11.2 3.7 (min:1.0, max:17.8). 37.9\% of children ( $n=99$ ) were obese, $27.6 \%$ of children ( $n=72$ ) were underweight according to age and $34.5 \%$ of children ( $n=90$, control group) were normal. The hemoglobin level and MPV was within normal range in all children; however they were higher in obese and control group when compared with underweight group. The statistical difference was detected for MPV among those with and without insulin resistance.

Conclusion: We detected that MPV levels were low in underweight children when compared with obese and normal weight group, which was not compatible with literature. However all levels were within normal limits. We established that insulin resistance does not affect MPV levels. More studies are needed concerning the use of MPV level in clinical practise.

Key words: pediatrics, adolescence, body mass index, MPV, isulin resistance, hepatosteosis

\section{Giriş}

Ortalama trombosit volümü (MPV), dolaşımdaki plateletlerin ortalama büyüklüğünü gösteren bir parametredir ve femtolitre (fl) olarak ifade edilir. Özellikle trombositopeni durumlarında MPV hastalık tanısı ile ilgili yol gösterici olabilir. Genç trombositler daha iri olup MPV değerini yükseltirler ve trombositopenik hastada kemik iliğinin çalıştığını gösterirler. Trombositopenik bireyde düşük MPV değeri ise kemik iliği süpresyonunu işaret ediyor olabilir. Trombosit fonksiyonları, büyüklükleri ile korele olabilir; çünkü iri plateletler daha aktiftir, daha çok sekretuar granül içerirler ve agregasyonda önemli olan tromboksan A2'yi daha çok üretirler [1]. Birçok klinisyen hemogram yorumlanmasında MPV değerlerini dikkate almamaktadır. Ancak güncel literatür incelendiğinde MPV değerinin sepsis, inflamatuar durumlar, kardiyovasküler hastalık riski, venöz tromboembolizm ve diabet gibi bazı hastalıklarda tanısal faydası olabileceği belirtilmektedir [2-5].

Obez adölesanlarda MPV değerinin obez olmayanlara göre yükseldiği birkaç çalışmada gösterilmiştir [6-8]. Çocukluk çağındaki çalışmalar daha çok adölesan dönemi içermektedir. Daha küu̧ük yaştaki çocuklardaki obezitenin MPV değerine etkisi yeni bir araştırma konusudur. Ayrıca yaşa göre düşük vücut kitle indeksi (VKi) olan hastalarda MPV değişiklikleri tanımlanmamıştır.

$\mathrm{Bu}$ çalışmanın birinci sonlanım noktası obez, yaşa göre normal ve düşük VKi'ne sahip çocuk ve adölesanlarda MPV değerlerinin incelenmesi, VKi ile MPV değerleri arasındaki ilişkinin araştııımasıdır. İkinci sonlanım noktası ise obez hastalarda insulin direnci ve hepatosteatoz varlığına göre MPV değerlerinde değişiklik olup olmadığını değerlendirmektir.

\section{Gereç ve Yöntemler}

Retrospektif olarak Ağustos 2012-Nisan 2015 tarihleri arasında Edirne Devlet Hastanesi Çocuk Endokrinoloji Polikliniğine başvuran hastaların dosyaları incelendi. Hastane bilgi yönetim sistemine kayıtlı otomatik kan sayımı olan hastalar randomize olarak çalışmaya dahil edildi. Bilinen bir hastalığı olan, enfeksiyonu olan veya ilaç kullanan hastalar çalışma dışı bırakıldı. Hasta verilerinden VKi, vücut ağırlığı/ boy ${ }^{2}(\mathrm{~kg} /$ $\mathrm{m}^{2}$ ) olarak hesaplandı. Pubertal gelişim evresi fizik muayene bilgilerinden edinilen bilgiye göre Tanner evrelemesine göre yapıldı [9-10]. İnsülin direnci literatüre dayanarak hesaplandı [11]. Obez hastalarda abdominal ultrasonografi yapılmış olanlarda hepatosteatoz olup olmadığı kaydedildi. Hastalar VKi'ye göre üç gruba ayrıldı:

1. Grup (obez grup): $\mathrm{VKI}>+2 \mathrm{SD}$

2. Grup (yaşa göre zayıf grup): (VKi<-2SD)

3. Grup (kontrol grubu= yaşa göre normal grup): VKI -2SD ile +2 SD olanlar

Grupların demografik özellikleri ve MPV değerleri karşılaştırıldı. Ayrıca obez grup kendi içinde insulin direnci ve hepatosteatoz varlığına göre alt gruplara bölünerek birbiriyle aynı parametreler açısından karşılaştıııldı.

Bu çalışma etik komite tarafından onaylanmış ve çalışmanın Helsinki Illkeler Deklerasyonuna uyularak gerçekleştirilmiştir.

\section{İstatistiksel analiz}

İstatistiksel analiz için SPSS version 17 kullanıldı. Verilerin normal dağılımı Kolmogorov-Smirnov testi ile değerlendirildi. Veriler normal dağılıma uyduğu için, ortalama \pm 2 SD kullanıldı. 
Gruplar ölçümsel değerler için parametrik testler (Student T test, One Way ANOVA) ile karşılaştırıldı. Çoklu varyans analizinde istatistiksel olarak anlamlı fark tespit edildiğinde post hoc testler (Tukey düzeltmeli One Way ANOVA) kullanıldı. Ordinal veriler ise Ki-kare testi ile karşılaştırıldı. $p<0,05$ değerler istatistiksel olarak anlamlı kabul edildi.

\section{Bulgular}

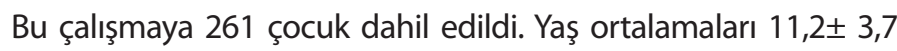
(min:1,0, max:17,8) olan çocukların \%57,1'i ( $n=149)$ kı, \% 42,9'u ( $n=112$ ) erkek olduğu; \%33,7'sinin prepubertal ( $n=88), \% 66,3$ 'ü ( $n=173)$ pubertal dönemde olduğu saptandı. Çalışmaya dahil olan çocukların \%37,9'u ( $n=99)$ obez, \%27,6'sı ( $n=72)$ yaşa göre zayıf, \%34,5 i ( $n=90$ ) ise normal ağırlıkta (kontrol grubu) bulundu (Tablo 1). Gruplar arasında yaş, cinsiyet ve pubertal durum açısından farklılık saptanmazken; vücut ağırlığı, boy-SD ve VKi değerlerinde üç grup arasında istatistiksel olarak anlamlı fark tespit edildi. Tüm hastaların hemoglobin (>11g/dl) ve MPV (7- 11 fl) değerlerinin normal sınırlarda olduğu görüldü. Ancak grupların ortalama hemoglobin ve MPV değerleri karşılaştırıldığında üç grup arasında istatistiksel olarak anlamlı fark tespit edildi (her iki parametre için $p<0,001)$. Farklılığı yaratan grup için ileri inceleme yapıldığında obez ve kontrol gruplarının ortalama hemoglobin ve MPV değerlerinin yaşa göre zayıf gruptan istatistiksel olarak anlamlı yüksek olduğu ancak obez ile kontrol grubu arasında fark olmadığı görüldü (Tablo 1). MPV ile VKI arasında zayıf pozitif korelasyon saptandı $(p<0,001, r=0,313)$.

Tablo 1. Hastaların tümünde ve $>11$ yaş olanlarda vücut kitle indeksine göre obez, normal ve zayıf olanlarda demografik özellik ve bazı hemogram parametrelerinin karşılaştırılması

\begin{tabular}{|c|c|c|c|c|c|}
\hline & & $\begin{array}{l}\text { Obez grup } \\
(\mathrm{n}=99)(\mathrm{a})\end{array}$ & $\begin{array}{l}\text { Yaşa göre zayılf } \\
\text { grup (n=72) (b) }\end{array}$ & $\begin{array}{l}\text { Kontrolgrubu } \\
(\mathrm{n}=90)(\mathrm{c})\end{array}$ & $p$ \\
\hline Yaş & & $\begin{array}{l}11,3 \pm 3,3 \\
(5,0-17)\end{array}$ & $\begin{array}{l}11,3 \pm 4,6 \\
(1,0-17,8)\end{array}$ & $\begin{array}{l}11,2 \pm 3,5 \\
(5,0-17,9)\end{array}$ & $>0,05$ \\
\hline \multirow[t]{2}{*}{ Cinsiyet } & $\mathrm{K} ı \mathrm{z}$ & $55(\% 56)$ & $39(\% 54)$ & $48(\% 53)$ & \multirow[t]{2}{*}{$>0,05$} \\
\hline & Erkek & $44(\% 44)$ & $33(\% 46)$ & $42(\% 47)$ & \\
\hline \multirow[t]{2}{*}{ Pubertal durum } & Prepubertal & $29(\% 29)$ & $21(\% 29)$ & $30 \% 33)$ & \multirow[t]{2}{*}{$>0,05$} \\
\hline & Pubertal & $70(\% 71)$ & $51(\% 71)$ & $60(\% 67)$ & \\
\hline Vücut ağırlı̆̆1 & & $\begin{array}{l}70 \pm 25 \\
(26-156)\end{array}$ & $\begin{array}{l}29 \pm 12 \\
(7-55) \\
\end{array}$ & $\begin{array}{l}39 \pm 16 \\
(16-84)\end{array}$ & $\begin{array}{l}<0,001 \\
\mathrm{a}>\mathrm{b}, \mathrm{a}>\mathrm{c}, \mathrm{c}>\mathrm{b}\end{array}$ \\
\hline Boy & & $\begin{array}{l}150 \pm 17 \\
(111-183)\end{array}$ & $\begin{array}{l}140 \pm 27 \\
(74-184)\end{array}$ & $\begin{array}{l}143 \pm 19 \\
(104-179)\end{array}$ & $\begin{array}{l}0,002 \\
\mathrm{a}>\mathrm{b}, \mathrm{a}>\mathrm{c}\end{array}$ \\
\hline Boy-SD & & $\begin{array}{l}0,9 \pm 1,1 \\
(-1,4-3,1)\end{array}$ & $\begin{array}{l}-0,7 \pm 1,1 \\
(-3,0-1,6)\end{array}$ & $\begin{array}{l}1,2 \pm 1,1 \\
(-2,0-2,0)\end{array}$ & $\begin{array}{l}<0,001 \\
\mathrm{a}>\mathrm{b}, \mathrm{a}>\mathrm{c}, \mathrm{b}>\mathrm{c}\end{array}$ \\
\hline $\begin{array}{l}\text { Vücut Kitle } \\
\text { indeksi }\end{array}$ & & $\begin{array}{l}30 \pm 5 \\
(21-48) \\
\end{array}$ & $\begin{array}{l}14 \pm 2 \\
(11-19) \\
\end{array}$ & $\begin{array}{l}18 \pm 4 \\
(13-29) \\
\end{array}$ & $\begin{array}{l}<0,001 \\
a>b, a>c, c>b\end{array}$ \\
\hline $\begin{array}{l}\text { Hemoglobin } \\
(\mathrm{g} / \mathrm{dl})\end{array}$ & & $\begin{array}{l}13,6 \pm 1,0 \\
(10-17)\end{array}$ & $\begin{array}{l}12,8 \pm 1 \\
(11-16)\end{array}$ & $\begin{array}{l}13,2 \pm 1,1 \\
(11-17)\end{array}$ & $\begin{array}{l}<0,001 \\
a>b, c>b\end{array}$ \\
\hline $\begin{array}{l}\text { MCV } \\
\text { (fl) }\end{array}$ & & $\begin{array}{l}83,6 \pm 6 \\
(58-98)\end{array}$ & $\begin{array}{l}83 \pm 5 \\
(72-92)\end{array}$ & $\begin{array}{l}84 \pm 6 \\
(60-103)\end{array}$ & $>0,05$ \\
\hline $\begin{array}{l}\text { MPV } \\
\text { (fl) }\end{array}$ & & $\begin{array}{l}9,3 \pm 1,1 \\
(6,3-11,9)\end{array}$ & $\begin{array}{l}8,3 \pm 1,1 \\
(6,1-11,7)\end{array}$ & $\begin{array}{l}8,9 \pm 1,0 \\
(6,0-10,7)\end{array}$ & \begin{tabular}{l|}
$<0,001$ \\
$\mathrm{a}>\mathrm{b}, \mathrm{c}>\mathrm{b}$ \\
\end{tabular} \\
\hline PDW & & $\begin{array}{l}15,5 \pm 0,6 \\
(13,0-18,2)\end{array}$ & $\begin{array}{l}15,8 \pm 2,0 \\
(10,0-21,2)\end{array}$ & $\begin{array}{l}15,6 \pm 1,2 \\
(10,8-21,0)\end{array}$ & $>0,05$ \\
\hline Platelet & & $\begin{array}{l}345 \pm 75 \\
(200-650) \\
\end{array}$ & $\begin{array}{l}310 \pm 100 \\
(175-590)\end{array}$ & $\begin{array}{l}320 \pm 70 \\
(210-700)\end{array}$ & $>0,05$ \\
\hline$>11$ yaș & $\begin{array}{l}\text { Hemoglobin } \\
(\mathrm{g} / \mathrm{dl})\end{array}$ & $\begin{array}{l}13,7 \pm 1,2 \\
(10,2-16,8)\end{array}$ & $\begin{array}{l}13,0 \pm 1,0 \\
(10,8-16,1)\end{array}$ & $\begin{array}{l}13,4 \pm 1,2 \\
(11,1-16,9)\end{array}$ & $\begin{array}{l}\mathrm{P}=0,007 \\
\mathrm{a}>\mathrm{b}\end{array}$ \\
\hline & $\begin{array}{l}\text { MCV } \\
\text { (fl) }\end{array}$ & $\begin{array}{l}9,4 \pm 1,1 \\
(7,5-12,0)\end{array}$ & $\begin{array}{l}8,5 \pm 1,0 \\
(6,8-11,0)\end{array}$ & $\begin{array}{l}9,1 \pm 1,0 \\
(6,8-10,7)\end{array}$ & $\begin{array}{l}\mathrm{p}<0,001 \\
\mathrm{a}>\mathrm{b}, \mathrm{c}>\mathrm{b}\end{array}$ \\
\hline
\end{tabular}

Sadece >11 yaş olan hastaların $(n=150)$ MPV değerleri karşılaştıııldığında da yaşa göre zayıf olanlarda kontrol ve obez gruba göre MPV değerinin istatistiksel olarak anlamlı derecede daha düşük olduğu $(p<0,001)$ ancak obez ve kontrol grubu arasında fark olmadığı görüldü. Benzer şekilde gruplar arasında hemoglobin değeri karşılaştırıldığında gruplar arası istatistiksel anlamlı fark olduğu görüldü ve bu farkın obez hastalarda ortalama hemoglobin değerinin yaşa göre zayıf olanlardan yüksek olmasına bağlı olduğu tespit edildi (Tablo 1).

Obez hastalar kendi içinde insulin direnci olmayanlar ( $n=$ 28) ve olanlar ( $n=62$ ) olarak iki gruba bölündüğünde, her iki

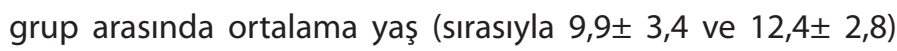
ve VKI (sırasıyla $27,4 \pm 4,8$ ve $31,2 \pm 5,0$ ) arasında istatistiksel olarak anlamlı fark saptanırken (her iki durum için $p<0,001$ ) hemoglobin, trombosit sayısı, MPV değerleri arasında anlamlı fark tespit edilmedi.

Obez hastalar içinde hepatosteatoz olmayanlar $(n=66)$ ile olanlar ( $n=31$ ) karşılaştırıldığında, ortalama VKi hepatosteatoz olanlarda istatistiksel olarak anlamlı yüksek saptandı (sırasıyla $28,1 \pm 4,4$ ve $33,2 \pm 5,4)(p<0,001)$. Ancak iki grup arasında ortalama hemoglobin, MPV, platelet değerleri arasında istatistiksel olarak anlamlı bir fark tespit edilmedi.

\section{Tartışma}

Bu çalışmada sayı, yaş ve cinsiyetleri birbirine yakın obez, normal(kontrol) ve yaşa göre zayıf hastalar MPV değerleri açısından karşılaştırılmış ve ortalama MPV değerleri obez ve kontrol grubunda istatistiksel olarak farklı çıkmamıştır. Ancak yaşa göre zayıf çocuklarda obez ve kontrol grubuna göre düşük saptanmıştır. Literatürde yaşa göre zayıf bireylerde MPV değerleriyle ilgili bir veriye rastlanmamıştır. Ancak Oświęcimska ve ark. [12] anoreksiya nevroza tanısı olan adölesan kızlarda MPV değerlerinin kontrol grubundan farklı olmadığını belirtmiş̧lerdir. Özkan ve ark. [6] obez 60 adölesan ve sağlıklı 48 adölesanın MPV değerlerini karşılaştırmış ve obez olanlarda istatistiksel olarak anlamlı derecede yüksek bulmuştur. Benzer şekilde Arslan ve ark. [8] çalışmasında da obez adölesanlarda ( $n=62$ ) ortalama MPV değerlerinin sağlıklı kontrol $(n=23)$ grubuna göre istatistiksel olarak anlamlı derecede yüksek bulmuşlardır. Bizim çalışmamızı oluşturan çocuk hastaların \%44'ü < 11 yaşta olup bu yaştaki çocuklardaki obezitenin laboratuar yansımasının adölesan gruba göre farklı olabileceğini düşündük. Obezite süresinin uzaması ilerleyici organ hasarı ile ilişkili olabilir. Her ne kadar çalışmamıza dahil olan hastaların uzun dönem takip verileri mevcut olmasa da, obezite eksojen kaynaklıydı ve yaş arttıkça obesite süresinin artmış olabileceği düşünüldü. MPV değerlerindeki değişikliklerin kronik süreçte olabileceği düşünüldü. Bu bakış 
açısıyla sadece adölesan dönemdeki çocukların ortalama MPV değerleri karşılaştıııldı. İlginç olarak adölesan çocuklarda da MPV değerinin kontrol ile obez grup arasında farklı olmadığı, ancak zayıf bireylerde daha düşük olduğu gösterildi.

Çalışmamızda obez hastalar içinde insülin direnci olanlar ve olmayanlar karşılaştıııldığında MPV değerleri arasında istatistiksel bir fark saptanmadı. Venkatesh ve ark. [3]yaptıkları çalışmada tip 1 diyabet mellitus tanısı olan $(n=130)$ pediatrik hastaların MPV değerlerinin sağılıkı kontrol grubuna $(n=130)$ göre yüksek olduğunu belirtmişlerdir. Ayrıca glisemik kontrolü iyi olmayan bireylerin de MPV değerlerinin iyi olanlardan yüksek olduğunu göstermişlerdir. Bu konuda daha çok çalışmaya ihtiyaç olduğu düşünülmüştür.

Arslan ve ark. [8] obez adölesanlarda artan hepatosteatoz ile MPV değerinin arttığını göstermişlerdir. Ancak bizim çalışmamızda hepatosteatoz ile MPV değerleri arasında ilişki kurulamadı.

Vücut metabolizması ve homeostaz bir bütündür ve birçok şeyden etkilenebilir. Benzer şekilde hemogram için kan alınma tekniği, alınan numunenin laboratuara ulaşıp çalışılma süresi, hemogram cihazlarının kalibrasyonu gibi parametreler de MPV değerlerinde farklıı̆ga neden olabilmektedir. Bu çalışmanın zayıf noktası bu parametrelerin standardize edilememiş olması olabilir. Ayrıca hemogram ile eş zamanlı periferik kan yaymasında plateletlerin değerlendirilmesi de sonuçların daha güvenilir olmasına katkı sağlayabilir.

\section{Sonuç}

Çalışmamızda literatürden farklı olarak MPV değerinin zayıf çocuklarda normal kiloda ve obez olanlara göre düşük, ancak hepsinde de normal aralıkta olduğunu saptadık. Insülin direncinin ve hepatosteatozun MPV değerlerine etkisi olmadığını gösterdik. MPV değerlerinin klinik uygulamalarda yeri ile ilgili daha çok çalışmaya ihtiyaç vardır.

\section{Çıkar çatışması / finansal destek beyanı}

Bu yazıdaki hiçbir yazarın herhangi bir çıkar çatışması yoktur. Yazının herhangi bir finansal desteği yoktur.

\section{Kaynaklar}

1. Thompson $C B$, Eaton $K A$, Princiotta $S M$, Rushin $C A$, Valeri $C R$. Size dependent platelet subpopulations: relationship of platelet volume to ultrastructure, enzymatic activity, and function. $\mathrm{Br} J$ Haematol 1982; 50: 509-19.

2. Chu SG, Becker RC, Berger PB et al. Mean platelet volume as a predictor of cardiovascular risk: a systematic review and metaanalysis. J Thromb Haemost 2010; 8: 148-56.
3. Venkatesh V, Kumar R, Varma DK, Bhatia P, Yadav J, Dayal D. Changes in platelet morphology indices in relation to duration of disease and glycemic control in children with type 1 diabetes mellitus. J Diabetes Complications 2018; 32: 833-38.

4. Dursun A, Ozsoylu S, Akyildiz BN. Neutrophil-to-lymphocyte ratio and mean platelet volume can be useful markers to predict sepsis in children. ak J Med Sci 2018; 34: 918-22.

5. Çelik SF, Çelik E. The neutrophil-to-lymphocyte ratio and mean platelet volume can be associated with severity of valvular involvement in patients with acute rheumatic carditis. Cardiovasc J Afr 2018; 23; 29: 296-300.

6. Özkan EA, Khosroshahi HE, Serin $\mathrm{HI}$ et al. The evaluation of carotid intima-media thickness and mean platelet volume values and correlation with cardiac functions in obese children. Int J Clin Exp Med 2015; 15; 8: 22557-63

7. Arslan N, Makay B, Hızlı S et al. Assessment of atherosclerosis in obese adolescents: positive correlation of mean platelet volume and carotid intima media thickness. J Paediatr Child Health 2013; 49: 963-68.

8. Arslan N, Makay B. Mean platelet volume in obese adolescents with nonalcoholic fatty liver disease. J Pediatr Endocrinol Metab 2010; 23: 807-13.

9. Marshall WA, Tanner JM. Variations in pattern of pubertal changes in girls. Arch Dis Child 1969; 44: 291-303.

10. Marshall WA, Tanner JM. Variations in the pattern of pubertal changes in boys. Arch Dis Child 1970; 45: 13-23.

11. Kurtoğlu S, Hatipoğlu N, Mazıcıoğlu M, Kendirici M, Keskin $M$, Kondolot M.Insulin resistance in obese children and adolescents: HOMA-IR cut-off levels in the prepubertal and pubertal periods. J Clin Res Pediatr Endocrinol 2010; 2: 100-6.

12. Oświęcimska J, Malczyk Ż, Szymlak A, et al. Changes in Platelet Count and Size Indices in Adolescent Patients With Anorexia Nervosa. Clin Appl Thromb Hemost 2017; 23: 562-566. 